Francomichele Puca, and The Italian Collaborative Group for the Study of Psychopathological Factors in Primary Headaches*

Received: 3 January 2000

Accepted in revised form: 27 March 2000

F. Puca (《)

Neurology Clinic, University of Bari,

Piazza Giulio Cesare 11, I-70124 Bari, Italy

e-mail: pressisc@tin.it,

f.m.puca@neurol.uniba.it

Tel.: +39-080-5473307

Fax: +39-080-5478532; +39-080-5593079

*Francomichele Puca, Sergio Genco, Maria Pia Prudenzano, Mariantonietta Savarese, Gennaro Bussone, Domenico D'Amico, Rosanna Cerbo, Costanzo Gala, Maria Teresa Coppola, Virgilio Gallai, Caterina Firenze, Paola Sarchielli, Mario Guazzelli, Vincenzo Guidetti, Gian Camillo Manzoni, Franco Granella, Alberto Muratorio, Ubaldo Bonuccelli, Angelo Nuti, Giuseppe Nappi, Giorgio Sandrini, Anna Pia Verri, Federigo Sicuteri, Simone Marabini.

\section{Psychological and social stressors and psychiatric comorbidity in patients with migraine without aura from headache centers in Italy: a comparison with tension-type headache patients}

\begin{abstract}
A multicenter study was carried out to investigate the prevalence of psychosocial stressors and psychiatric comorbidity in patients suffering from migraine without aura (MWO) according to the International Headache Society criteria. Two hundred four adult MWO outpatients underwent a structured psychiatric interview (CIDI-c) to determine the presence of anxiety, and mood and somatoform disorders according to DSM-III-R criteria. An ad hoc questionnaire was used to assess psychosocial stress events. Anxiety disorders were found in $39.2 \%$ of the sample, mood disorders occurred in $23.0 \%$ and somatoform disorders in $21.6 \%$. Psychosocial stressors were identified in $22.5 \%$ of the migraineurs without any difference between patients with and without psychiatric comorbidity. No correlation was found between psychi-
\end{abstract}

atric comorbidity and migraine duration or frequency. When the migraine patients were compared with a homogeneous group of tension-type headache sufferers, a higher frequency of psychiatric comorbidity was found in the latter group (56.4\% vs. $77.8 \%, p=0.01)$. These data suggest that migraine as well as tension-type headache are associated with an increased vulnerability to psychiatric disorders. Whether this is related to a common genetic susceptibility or is the effect of a psychoneurobiological loop related to the stress response activation remains to be investigated.

Key words Migraine without aura • Tension-type headache $\cdot$ Psychiatric comorbidity • DSM-III-R • IHS classification - Psychological stressors • Social stressors $\cdot$ Stress response

\section{Introduction}

Over the last few years, several studies, conducted both in the general population and in patients referred to headache centers, have indicated a high comorbidity between migraine and anxiety and mood disorders (especially panic attack disorders and major depression) [1-8]. Migraine is also associated with stressful life events, although the nature of their relation to migraine, i.e. causative or consequential, remains under dispute [9-22].

Stressful life events not only act as illness precursors or antecedents of headache [13]; they can be a consequence of the disorder and they can act as a mediating variable in the persistence of chronic headache $[14,15]$ or in the triggering of a migraine attack [21, 22].

Patients with migraine referred to tertiary headache care centers present with a more severe and disabling disturbance as compared to migraine sufferers from the general population who do not necessarily seek specialist care. Thus, migraine patients recruited in tertiary care centers represent an ideal population to investigate the reciprocal influence of headache, psychiatric disorders and stressful life events as migraine is expressed to the most severe degrees. One may expect, in fact, that higher patient disability is also associated with greater psychiatric comorbidity and/or psychosocial stressors. 
The aims of this study were to assess the prevalence of psychiatric comorbidity and stressful life events in patients with migraine referred to tertiary care headache centers in Italy and to compare the prevalence of psychosocial stressors in patients with and without psychiatric comorbidity.

Furthermore, we compared the migraine patients in this study to a large group of patients with episodic or chronic tension-type headache from a previously published report [23], to test the hypothesis that psychiatric comorbidities and/or psychosocial stressors in migraine patients are different than those in patients with tension-type headache.

\section{Patients and methods}

As a part of a larger collaborative project of the Italian Society for the Study of Headache, the present study was set up to assess the prevalence of psychosocial stressors and psychiatric disorders among patients affected by primary headaches. Here we report the results of a study in patients with migraine without aura (MWO). Two hundred four adult outpatients affected by migraine without aura referred for the first time to ten Italian tertiary care headache centers (Bari, Florence, Milan I, Milan II, Parma, Pavia, Perugia, Pisa, Rome I, Rome II), were consecutively recruited over a oneyear period from June 1993 to June 1994 (Table 1). The diagnosis was made according to the International Headache Society (IHS) criteria [24]. Inclusion criteria were: history of headache for at least 1 year, occurrence of at least 1 attack per week during the last 6 months, absence of other primary headaches or chronic somatic pains (e.g. back pain), and absence of a history of any recurrent headache, except for MWO.

A structured psychiatric interview, the Composite International Diagnostic Interview-Core (CIDI-c) [25], previously translated into Italian and validated for the Italian population [26], was administered to the patients by trained physicians in order to establish a DSM-III-R psychiatric diagnosis [27]. This interview focused on anxiety, mood and somatoform disorders. An ad hoc questionnaire was used to identify the occurrence of psychosocial stressors which were classified according to DSM-III-R criteria [27]. Inter-rater reliability among physicians was previously established in an ad hoc trial.

A sample of 217 patients with episodic (ETT) or chronic (CTT) tension-type headache previously studied with the same

Table 1 Demographic characteristics of the study sample. Values in parentheses are standard deviations

\begin{tabular}{lccc}
\hline & $\begin{array}{c}\text { Migraine } \\
\text { without aura }\end{array}$ & $\begin{array}{c}\text { Tension-type } \\
\text { headache }\end{array}$ & Total \\
\hline Number of cases & 204 & 217 & 421 \\
Males & 45 & 76 & 121 \\
$\begin{array}{l}\text { Females } \\
\text { Mean age, years }\end{array}$ & 159 & 141 & 300 \\
$\begin{array}{l}\text { Mean age at headache } \\
\text { onset, years }\end{array}$ & $19.5(10.6)$ & $36.3(12.2)$ & $35.5(11.7)$ \\
\hline
\end{tabular}

methods by our group [23] was used for comparisons (Table 1).

Univariate statistical analysis was carried out using chi-square and Fisher's exact tests, when appropriate. A logistic regression was performed to assess the association of psychiatric comorbidity with age of patients, migraine duration and frequency of attacks. Then, the correspondence analysis was applied to the whole sample consisting of 204 migraineurs and 217 tension-type headache sufferers. For this analysis, the group of 217 tension-type headache patients was further subdivided in four samples: (1) patients with episodic tension-type headache with pericranial muscle disorder (ETTw) (40 cases); (2) patients with episodic tension-type headache without pericranial muscle disorder (ETTwo) (68 cases); (3) patients with chronic tension-type headache with pericranial muscle disorder (CTTw) (59 cases); and (4) patients with chronic tension-type headache without pericranial muscle disorder (CTTwo) (50 cases). Using correspondence analysis, a contingency table was obtained in which the rows represented the five kinds of headaches (MWO, ETTw, ETTwo, CTTw, CTTwo) and the columns represented the psychiatric categories (anxiety disorders, mood disorders, somatoform disorders, psychosocial stresses). In the graphs, the intersection of the two axes corresponds to the mean profile. Graphically, the farther a point is from the origin, the greater is the association between rows and columns. The proximity between two row points or between two column points indicates a strong correlation in the data. The correspondence between a row point and a column point can be interpreted by the angle between them, taking the origin as the summit. If the angle is acute $\left(<90^{\circ}\right)$, the two items represented by the points are positively correlated. If the angle is obtuse the points are negatively correlated, and if there is a right angle the points do not interact. Statistical analyses were performed by using the SAS statistical software package (SAS Institute, Milan, Italy).

\section{Results}

One hundred thirty-five patients $(66.2 \%)$ out of the 204 examined showed at least one psychiatric disorder or psychosocial stressor. A single associated psychosocial stress or psychiatric disorder was identified in 74 (54.8\%) of these patients; 44 patients $(32.6 \%$ ) had two disorders, 13 patients (9.6\%) had three, and 4 patients (3.0\%) had four disorders.

Psychosocial stresses were found in 46 patients (22.5\%), including 9 males (20.0\%) and 37 females (23.3\%); the gender difference was not statistically significant (Table 2). Among the psychiatric disorders, anxiety was by far the most represented, being present in 80 cases (39.2\%). Its prevalence was significantly higher in females (69 cases, $43.4 \%$ ) than in males (11 cases, $24.4 \%$ ), $p<0.05$. Mood disorders were found in 47 cases (23.0\%) without any significant gender difference: 6 males, (13.3\%) vs. 41 females (25.8\%). Somatoform disorders were diagnosed in 44 subjects (21.6\%); no difference was found between males (6 cases, $13.3 \%$ ) and females (38 cases, $23.9 \%$ ).

The distinct psychosocial stressors and psychiatric diagnoses are reported in Table 2. Psychosocial stress was most- 
Table 2 Psychopathological disorders according to DSM-III-R in the 204 patients affected by migraine without aura. The number of psychopathological disorders exceeds the number of patients because some patients presented more than one disorder

\begin{tabular}{|c|c|c|c|c|c|c|}
\hline Psychopathological disorders & \multicolumn{2}{|c|}{ Males } & & $\begin{array}{l}\text { ales } \\
(\%)^{\mathrm{b}}\end{array}$ & ${ }_{n}^{\mathrm{T}}$ & $\begin{array}{l}\text { tal } \\
(\%)^{\mathrm{c}}\end{array}$ \\
\hline Psychosocial stresses $(n=46)$ & 9 & $(20.0)$ & 37 & $(23.3)$ & 46 & $(22.5)$ \\
\hline Conjugal & 2 & $(4.4)$ & 9 & $(5.7)$ & 11 & $(5.4)$ \\
\hline Parenting & 0 & $(0)$ & 5 & $(3.1)$ & 5 & $(2.5)$ \\
\hline Other interpersonal & 1 & $(2.2)$ & 10 & $(6.3)$ & 11 & (5.4) \\
\hline Occupational & 4 & $(8.9)$ & 4 & $(2.5)$ & 8 & (3.9) \\
\hline Living circumstances & 1 & $(2.2)$ & 9 & $(5.7)$ & 10 & (4.9) \\
\hline Financial & 1 & $(2.2)$ & 2 & $(1.3)$ & 3 & $(1.5)$ \\
\hline Legal & 0 & $(0)$ & 3 & (1.9) & 3 & $(1.5)$ \\
\hline Developmental & 0 & $(0)$ & 2 & $(1.3)$ & 2 & $(1.0)$ \\
\hline Physical illness or injury & 0 & $(0)$ & 4 & $(2.5)$ & 4 & $(2.0)$ \\
\hline Other & 1 & $(2.2)$ & 0 & (0) & 1 & $(0.5)$ \\
\hline Anxiety disorders $(n=80)$ & 11 & $(24.4)^{*}$ & 69 & $(43.4)^{*}$ & 80 & $(39.2)$ \\
\hline Generalized anxiety disorder & 9 & $(20.0)$ & 45 & $(28.3)$ & 54 & $(26.5)$ \\
\hline Panic disorder without agoraphobia & 0 & $(0)$ & 4 & $(25.2)$ & 4 & $(19.6)$ \\
\hline Panic disorder with agoraphobia & 0 & $(0)$ & 1 & $(0.6)$ & 1 & $(0.5)$ \\
\hline Agoraphobia without history of panic disorder & 0 & $(0)$ & 2 & $(1.3)$ & 2 & $(1.0)$ \\
\hline Social phobia & 1 & $(2.2)$ & 1 & $(0.6)$ & 2 & $(1.0)$ \\
\hline Simple phobia & 3 & $(6.7)$ & 21 & $(13.2)$ & 24 & $(11.8)$ \\
\hline Obsessive-compulsive disorder & 0 & $(0)$ & 5 & $(3.1)$ & 5 & $(2.5)$ \\
\hline Adjustment disorder with anxious mood & 0 & $(0)$ & 1 & $(0.6)$ & 1 & $(0.5)$ \\
\hline Mood disorders $(n=47)$ & 6 & $(13.3)$ & 41 & $(25.8)$ & 47 & $(23.0)$ \\
\hline Dysthymia & 3 & $(6.7)$ & 21 & $(13.2)$ & 24 & $(11.8)$ \\
\hline Major depression, recurrent & 2 & $(4.4)$ & 9 & $(5.7)$ & 11 & $(5.4)$ \\
\hline Major depression, single episode & 0 & $(0)$ & 9 & $(5.7)$ & 9 & $(4.4)$ \\
\hline Bipolar disorder & 0 & $(0)$ & 1 & $(0.6)$ & 1 & $(0.5)$ \\
\hline Depressive disorder not otherwise specified & 1 & $(2.2)$ & 0 & (0) & 1 & $(0.5)$ \\
\hline Adjustment disorder with depressed mood & 0 & $(0)$ & 1 & $(0.6)$ & 1 & $(0.5)$ \\
\hline Somatoform disorders $(n=44)$ & 6 & $(13.3)$ & 38 & $(24.9)$ & 44 & $(21.6)$ \\
\hline Somatization disorder & 0 & (0) & 3 & $(1.9)$ & 3 & $(1.5)$ \\
\hline Undifferentiated somatoform disorder & 6 & $(13.3)$ & 35 & $(22.0)$ & 41 & $(20.1)$ \\
\hline
\end{tabular}

${ }^{*} p=0.03, \chi^{2}$ test for females vs. males

a Percent with respect to a total of 45 male patients

b Percent with respect to a total of 159 female patients

${ }^{c}$ Percent with respect to all 204 patients

ly represented in the marital $(5.4 \%)$, interpersonal $(5.4 \%)$, living environment $(4.9 \%)$ and occupational $(3.9 \%)$ areas.

Generalized anxiety disorder $(26.5 \%)$, panic disorder without agoraphobia (19.6\%) and simple phobia (11.8\%) prevailed among the anxiety group, while dysthymia (11.8\%), and recurrent (5.4\%) and single-episode (4.4\%) major depressions accounted for most of the mood disorders. Undifferentiated somatoform disorder (20.1\%) was the most frequent disorder in the somatoform group.

No significant difference was found in psychiatric comorbidity between patients with and without psychosocial stresses, either in the whole sample (26 cases $(12.7 \%)$ vs. 20 cases $(9.8 \%), p=n s)$ or in the female (24 cases
$(15.1 \%)$ vs. 13 cases $(8.2 \%), p=n s)$ or male $(2$ cases $(4.4 \%)$ vs. 7 cases $(15.6 \%), p=n s)$ groups.

Forty-eight patients showed more than one psychiatric disorder, as indicated in Table 3. Anxiety was the most represented disorder both alone and in association with other psychiatric disorders. The results of logistic regression showed that neither the age of the patients $(r=0.1, p=0.6)$ nor the migraine duration $(r=0.0, p=0.6)$ or frequency ( $r=0.0, p=0.6$ ) was correlated with the occurrence of psychopathology.

When the migraine patients were compared with a homogeneous group of tension-type headache (TTH) sufferers (Table 4), a higher frequency of psychiatric comor- 
Table 3 Psychiatric disorders in the 45 male and 159 female patients with migraine without aura. The number of psychosocial stress and psychiatric disorders exceeds number of patients because of multiple occurrences in some patients

\begin{tabular}{|c|c|c|c|c|}
\hline Psychiatric profile & $\begin{array}{l}\text { Males } \\
\mathrm{n} \quad(\%)^{\mathrm{a}}\end{array}$ & $\begin{array}{l}\text { Females } \\
\mathrm{n} \quad(\%)^{\mathrm{b}}\end{array}$ & & $\begin{array}{l}\text { otal } \\
(\%)^{\mathrm{c}}\end{array}$ \\
\hline No psychiatric disorders & $27(60.0)^{*}$ & $62(38.9)^{*}$ & 89 & $(43.7)$ \\
\hline Anxiety disorders & $6 \quad(13.3)$ & $32 \quad(20.1)$ & 38 & $(18.6)$ \\
\hline Mood disorders & $3 \quad(6.7)$ & $13 \quad(8.2)$ & 16 & $(7.8)$ \\
\hline Somatoform disorders & $4 \quad(8.9)$ & $(5.7)$ & 13 & $(6.4)$ \\
\hline Anxiety and mood disorders & $3 \quad(6.7)$ & $(8.8)$ & 17 & $(8.3)$ \\
\hline Anxiety and somatoform disorders & $2 \quad(4.4)$ & $(9.4)$ & 17 & $(8.3)$ \\
\hline Anxiety, mood and somatoform disorders & $(0)$ & $(5.0)$ & 8 & (3.9) \\
\hline Mood and somatoform disorders & $(0)$ & $(3.8)$ & 6 & (2.9) \\
\hline
\end{tabular}

$* p=0.007, \chi^{2}$ test for males vs. females

a Percent with respect to the 45 male patients

${ }^{\mathrm{b}}$ Percent with respect to the 159 female patients

${ }^{\mathrm{c}}$ Percent with respect to all 204 patients

Table 4 Psychological stress and psychiatric disorders in the 204 patients with migraine without aura and in the 217 patients with tension-type headache. The number of cases of psychosocial stress and psychiatric disorders exceeds the number of patients because of multiple occurrences in some patients

\begin{tabular}{lrrrr}
\hline & $\begin{array}{c}\text { Migraine without aura } \\
\mathrm{n}(\%)\end{array}$ & $\begin{array}{c}\text { Tension-type headache } \\
\mathrm{n}(\%)\end{array}$ & $p$ \\
\hline Any psychiatric comorbidity & 115 & $(56.4)$ & $169 \quad(77.8)$ & 0.01 \\
Psychosocial stress & 46 & $(22.5)$ & $64 \quad(29.5)$ & $\mathrm{ns}$ \\
Anxiety disorders & 80 & $(39.2)$ & $80 \quad(36.8)$ & 0.003 \\
Mood disorders & 47 & $(23.0)$ & $47 \quad(21.7)$ & 0.002 \\
Somatoform disorders & $44 \quad(21.6)$ & $\mathrm{ns}$ & \\
\hline
\end{tabular}

$n s$, not signficant

bidity was found in the latter group $(56.4 \%$ vs. $77.8 \%$, $p=0.01)$. Both anxiety and mood disorders were more represented in the TTH group while no significant difference was found in psychosocial stresses and somatoform disorders prevalences in the two headache subtypes.

The distinct psychosocial stressors and psychiatric diagnoses found in the MWO and TTH groups are reported in Table 5. When the individual psychiatric disorders in the two groups were compared, as shown in Table 6, mood disorders were more represented in the tension-type headache sample (16 cases $(7.8 \%)$ vs. 32 cases $(14.7 \%), p$ $<0.05)$.

The correspondence analysis derived from a contingency table in which the rows represent five kinds of headache and the columns represented the psychiatric cat- egories is shown in Figs. 1-5. Figure 1 indicates that migraine without aura was strongly correlated (narrow angles) with no anxiety disorders, no mood disorders, and no psychosocial stresses. Episodic tension-type headache without pericranial muscle disorder (Fig. 2) and episodic tension-type headache with pericranial muscle disorder (Fig. 3) are interrelated because by correspondence analysis their points lie close by in the same quadrant; both correlated (narrow angles) with psychosocial stresses and no somatoform disorders. Chronic tension-type headache without pericranial muscle disorder was highly correlated with somatoform disorders and with no psychosocial stresses (Fig. 4). Chronic tension-type headache with pericranial muscle disorder correlated with anxiety and depression (Fig. 5). 
Table 5 Psychopathological disorders according to DSM-III-R in the 204 patients affected by migraine without aura and in the 217 patients with tension-type headache. The number of psychopathological disorders exceeds the number of patients because some patients presented more than one disorder

\begin{tabular}{|c|c|c|c|c|}
\hline Psychopathological disorders & $\begin{array}{c}\text { Migraine } \\
\mathrm{n}\end{array}$ & $\begin{array}{l}\text { without aura } \\
(\%)^{\mathrm{a}}\end{array}$ & $\begin{array}{c}\text { Tension-typ } \\
n\end{array}$ & $\begin{array}{l}\text { pe headache } \\
(\%)^{\mathrm{b}}\end{array}$ \\
\hline $\begin{array}{l}\text { Psychosocial stress } \\
\text { Conjugal } \\
\text { Parenting } \\
\text { Other interpersonal } \\
\text { Occupational } \\
\text { Living circumstances } \\
\text { Financial } \\
\text { Legal } \\
\text { Developmental } \\
\text { Physical illness or injury } \\
\text { Other }\end{array}$ & $\begin{array}{r}46 \\
11 \\
5 \\
11 \\
8 \\
10 \\
3 \\
3 \\
2 \\
4 \\
1\end{array}$ & $\begin{array}{r}(22.5) \\
(5.4) \\
(2.5) \\
(5.4) \\
(3.9) \\
(4.9) \\
(1.5) \\
(1.5) \\
(1.0) \\
(2.0) \\
(0.5)\end{array}$ & $\begin{array}{r}64 \\
16 \\
13 \\
12 \\
31 \\
17 \\
0 \\
0 \\
0 \\
3 \\
0\end{array}$ & $\begin{array}{r}(29.5) \\
(7.4) \\
(5.9) \\
(5.5) \\
(14.3) \\
(7.8) \\
(0) \\
(0) \\
(0) \\
(1.4) \\
(0)\end{array}$ \\
\hline $\begin{array}{l}\text { Anxiety disorders } \\
\text { Generalized anxiety disorder } \\
\text { Panic disorder without agoraphobia } \\
\text { Panic disorder with agoraphobia } \\
\text { Agoraphobia without history of panic disorder } \\
\text { Social phobia } \\
\text { Simple phobia } \\
\text { Obsessive-compulsive disorder } \\
\text { Adjustment disorder with anxious mood } \\
\text { Post-traumatic stress disorder }\end{array}$ & $\begin{array}{r}80 \\
54 \\
4 \\
1 \\
2 \\
2 \\
24 \\
5 \\
1 \\
0\end{array}$ & $\begin{array}{r}(39.2) \\
(26.5) \\
(19.6) \\
(0.5) \\
(1.0) \\
(1.0) \\
(11.8) \\
(2.5) \\
(0.5) \\
(0)\end{array}$ & $\begin{array}{r}116 \\
97 \\
5 \\
4 \\
8 \\
14 \\
1 \\
0 \\
0 \\
1\end{array}$ & $\begin{array}{r}(53.4) \\
(44.7) \\
(2.3) \\
(1.8) \\
(3.7) \\
(6.4) \\
(0.5) \\
(0) \\
(0) \\
(0.5)\end{array}$ \\
\hline $\begin{array}{l}\text { Mood disorders } \\
\text { Dysthymia } \\
\text { Major depression, recurrent } \\
\text { Major depression, single episode } \\
\text { Bipolar disorder } \\
\text { Depressive disorder not otherwise specified } \\
\text { Cyclothymia } \\
\text { Adjustment disorder with depressed mood }\end{array}$ & $\begin{array}{r}47 \\
24 \\
11 \\
9 \\
1 \\
1 \\
0 \\
1\end{array}$ & $\begin{array}{r}(23.0) \\
(11.8) \\
(5.4) \\
(4.4) \\
(0.5) \\
(0.5) \\
(0) \\
(0.5)\end{array}$ & $\begin{array}{r}80 \\
36 \\
27 \\
9 \\
0 \\
7 \\
1 \\
0\end{array}$ & $\begin{array}{r}(36.9) \\
(16.6) \\
(12.4) \\
(4.1) \\
(0) \\
(3.2) \\
(0.5) \\
(0)\end{array}$ \\
\hline $\begin{array}{l}\text { Somatoform disorders } \\
\text { Body dysmorphic disorder } \\
\text { Conversion disorder } \\
\text { Hypochondriasis } \\
\text { Somatoform pain disorder } \\
\text { Somatization disorder } \\
\text { Undifferentiated somatoform disorder }\end{array}$ & $\begin{array}{r}44 \\
0 \\
0 \\
0 \\
0 \\
3 \\
41\end{array}$ & $\begin{array}{r}(21.6) \\
(0) \\
(0) \\
(0) \\
(0) \\
(1.5) \\
(20.1)\end{array}$ & $\begin{array}{r}47 \\
0 \\
0 \\
1 \\
7 \\
1 \\
38\end{array}$ & $\begin{array}{r}(21.6) \\
(0) \\
(0) \\
(0.5) \\
(3.2) \\
(0.5) \\
(17.5)\end{array}$ \\
\hline
\end{tabular}

a Percent with respect to a total of 204 patients with migraine without aura

${ }^{b}$ Percent with respect to a total of 217 patients with tension-type headache

Table 6 Psychiatric disorders in the 204 patients with migraine without aura and in the 217 patients with tension-type headache. The number of psychosocial stress and psychiatric disorders exceeds the number of patients because of multiple occurrences in some patients

\begin{tabular}{|c|c|c|c|c|c|}
\hline Psychiatric profile & $\begin{array}{c}\text { Migraine } \\
\mathrm{n}\end{array}$ & $\begin{array}{l}\text { vithout aura } \\
(\%)\end{array}$ & $\begin{array}{c}\text { Tension- } \mathrm{t} \\
\mathrm{n}\end{array}$ & $\begin{array}{l}\text { pe headache } \\
(\%)\end{array}$ & $p$ \\
\hline No psychiatric disorders & 89 & $(43.7)$ & 49 & $(22.6)$ & $0.0001^{\mathrm{a}}$ \\
\hline Anxiety disorders & 38 & $(18.6)$ & 57 & $(26.3)$ & - \\
\hline Mood disorders & 16 & $(7.8)$ & 32 & $(14.7)$ & $0.038^{\mathrm{a}}$ \\
\hline Somatoform disorders & 13 & (6.4) & 16 & $(7.4)$ & - \\
\hline Anxiety and mood disorders & 17 & $(8.3)$ & 25 & $(11.5)$ & - \\
\hline Anxiety and somatoform disorders & 17 & $(8.3)$ & 22 & $(10.1)$ & - \\
\hline Anxiety, mood and somatoform disorders & 8 & (3.9) & 12 & (5.5) & - \\
\hline Mood and somatoform disorders & 6 & (2.9) & 4 & (1.8) & $\mathrm{ns}^{\mathrm{b}}$ \\
\hline
\end{tabular}

$\chi^{2}$ test

b Fisher's exact test

$n s$, not significant 
Fig. 1 Correspondence analysis reveals strong correlation (narrow angles) between migraine without aura $(M W O)$ and absence of stress, anxiety or mood disorders
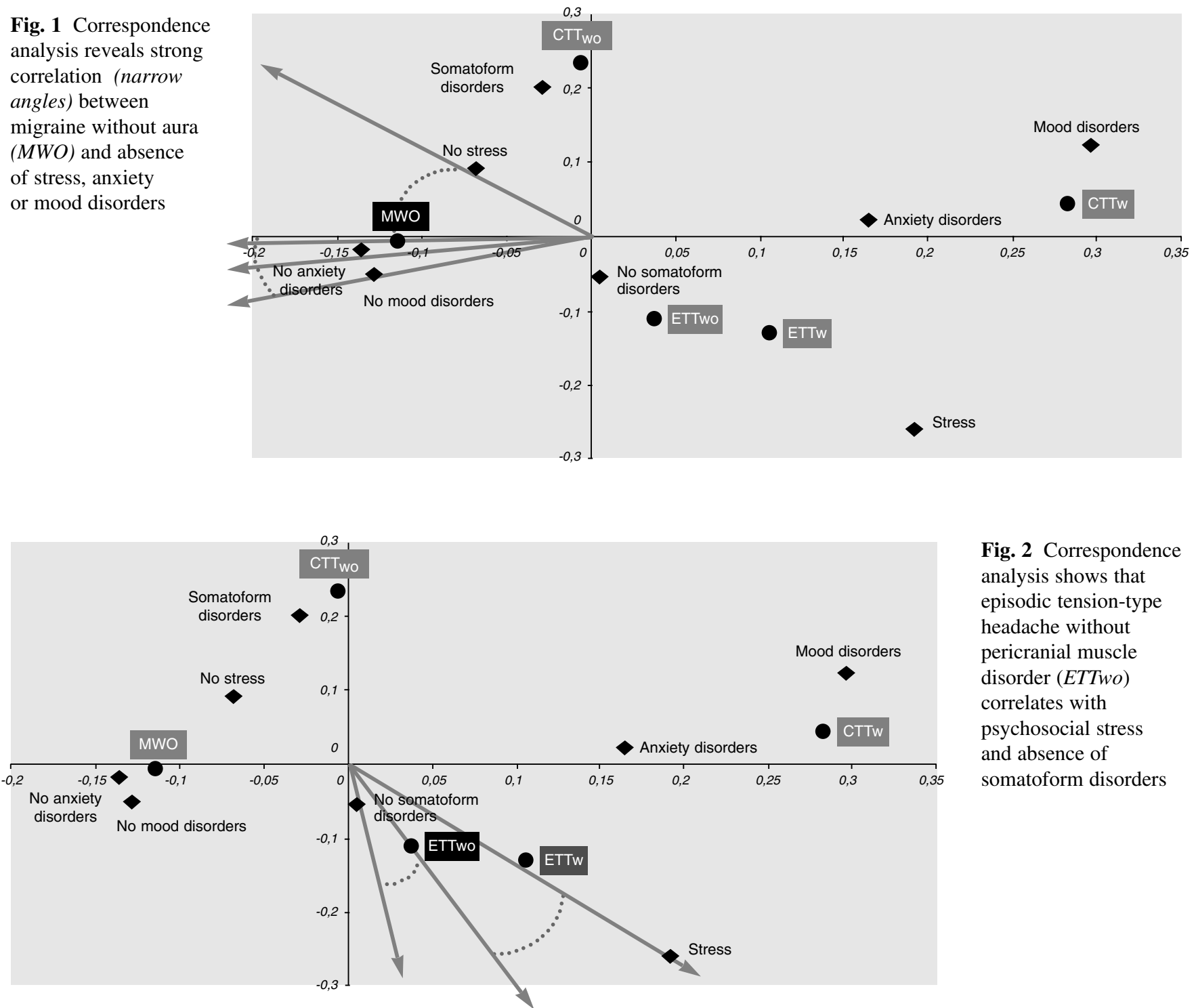

Fig. 2 Correspondence analysis shows that episodic tension-type headache without pericranial muscle disorder (ETTwo) correlates with psychosocial stress and absence of somatoform disorders

Fig. 3 Correspondence analysis indicates that episodic tension-type headache without pericranial muscle disorder (ETTw) correlates with psychosocial stress and absence of somatoform disorders

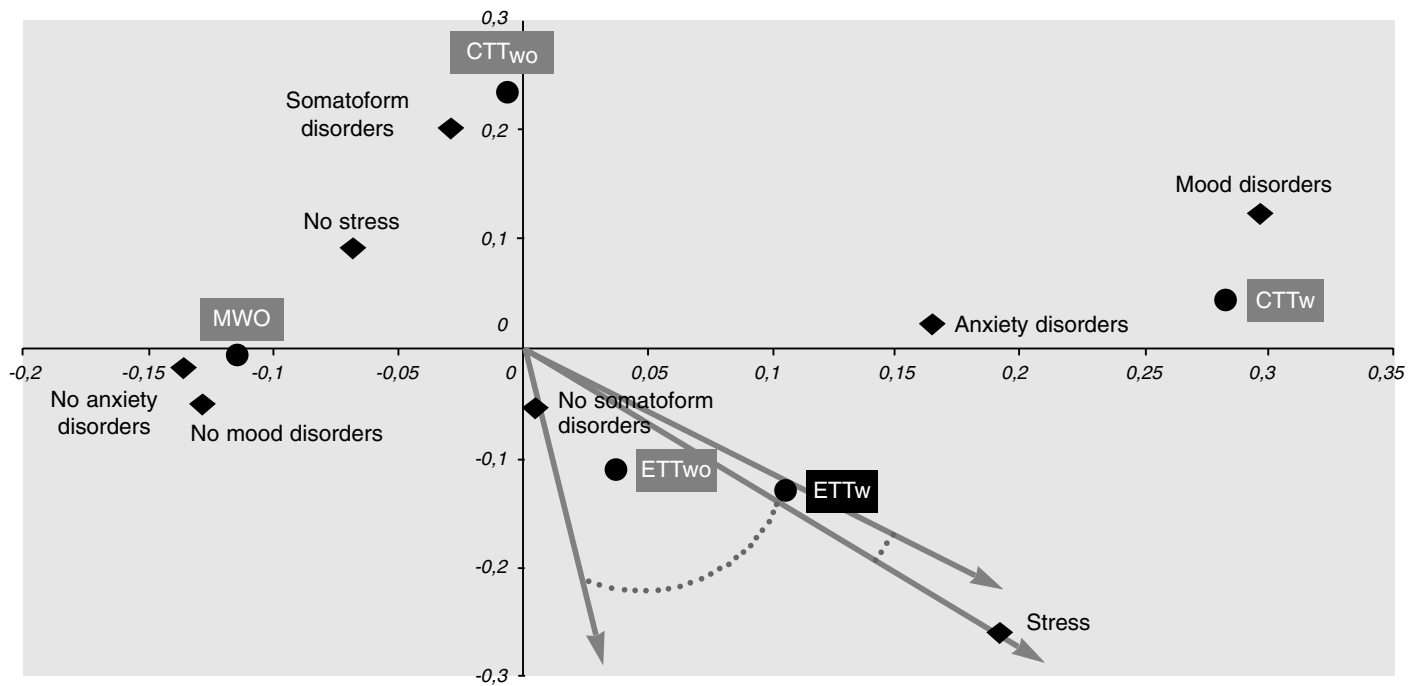


Fig. 4 Correspondence analysis reveals that chronic tension-type headache without pericranial muscle disorder (CTTwo) is strongly correlated with somatoform disorders and the absence of stress
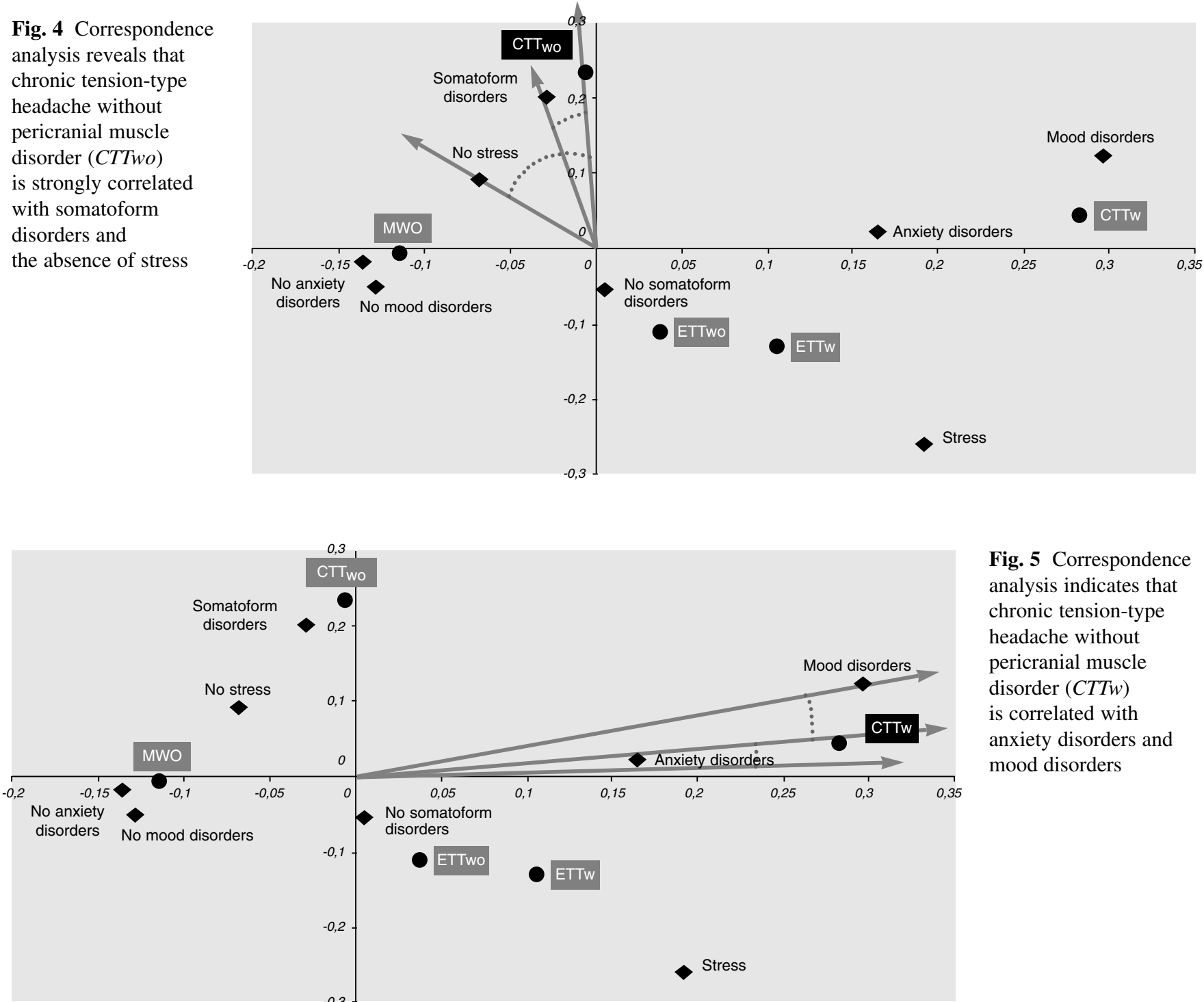

Fig. 5 Correspondence analysis indicates that chronic tension-type headache without pericranial muscle disorder (CTTw) is correlated with anxiety disorders and mood disorders

\section{Discussion}

We evaluated the prevalence of psychiatric morbidity and psychosocial stressors in outpatients affected by migraine without aura referred to ten Italian headache centers over a one-year period. Two-thirds of patients had at least one psychiatric disorder or psychosocial stress. Although we did not measure psychiatric comorbidity in a control group of subjects without migraine from the general population, these values are well above the previously reported prevalence [28, 29].

Anxiety was the prevalent disorder in the patients with psychiatric comorbidity, followed by mood and somatoform disorders. Among anxiety disorders, the most common was generalized anxiety disorder, followed by panic attack disorder without agoraphobia and simple phobia. Among mood disorders, dysthymia prevailed over major depression. These results are in agreement with, and further support, the data in the literature that indicate a higher prevalence of psychiatric comorbidity in patients with migraine without aura than in the general population $[1,2,4]$.

In migraine patients, psychiatric comorbidity or life stressors did not correlate either with the duration of migraine or with the frequency of attacks. The absence of a relation between the duration of the disease and the frequency of attacks on one hand and the prevalence of psychiatric comorbidity on the other suggest that the presence of psychiatric disorders is not a reaction to the "psychological load" of the painful migraine episodes, as had been indicated by several clinical studies $[1,6]$.

Women had a significantly greater psychiatric comorbidity than men, which could reflect the greater prevalence of psychiatric disorders, and particularly depression, generally 
observed in females [6]. The large numeric discrepancy between men and women in our sample, however, warrants caution in drawing any conclusion. Among the stressful life events examined, none appeared to predominate over others. Furthermore, no difference in the prevalence of life stresses was observed between the migraine patients with and without psychiatric comorbidity. These results suggest that stressful life events in migraine patients do not affect the probability of developing a concomitant psychiatric disorder, although prolonged stressful conditions may trigger a psychobiochemical loop leading to increased psychiatric vulnerability [10].

Psychiatric comorbidity in patients with migraine was compared with that in a group of patients with tension-type headache who had been recruited by the ten centers during the same period and whose data have already been reported [23]. Prevalence of psychiatric comorbidity in the migraine patients was lower than in the tension-type headache patients as a group. Episodic tension-type headache subgroups showed a positive relation with stress factors. Furthermore, a positive relation between psychopathological items and chronic tension-type headache subgroups was revealed by correspondence analysis. In fact, chronic tension-type headache with pericranial muscle disorder correlated with anxiety and depression whereas chronic tension- type headache without pericranial muscle disorder was highly correlated with somatoform disorders.

Altogether, these data may be subjected to different interpretations. Some authors have suggested a possible common genetic susceptibility between migraine and mood disorders [7]. In alternative, the association between headache and psychopathology can be seen as the consequence of the activation of stress-related phenomena that increase individual vulnerability to the onset of psychopathological manifestations [10]. A wide body of literature concordantly shows that the duration of a stressful event, in addition to and even more so than its intensity, plays a role in determining a psychopathological consequence [30-32]. This is be consistent with the observation that sporadic events such as psychological stresses are not associated with a greater prevalence of psychiatric comorbidity. In episodic tension-type and migraine headaches that show an increasingly greater degree of discomfort, there is a parallel increase of psychiatric comorbidity. The greatest degree of psychiatric morbidity, though, is seen in chronic tension-type headache where the discomfort, even if with a lesser intensity, persists. A bidirectional, circular model with changes in levels of stressors and psychiatric concomitants affecting headache and vice versa may provide an adequate explanation of these results [16-19].

\section{References}

1. Morrison DP, Price WH (1989) The prevalence of psychiatric disorders among female new referrals to a migraine clinic. Psychol Med 19:919-925

2. Merikangas KR, Angst J, Isler $H$ (1990) Migraine and psychopathology results of the Zurich Cohort Study of Young Adults. Arch Gen Psychiatry 47:850-853

2. Puca F, Genco S, Savarese M, Prudenzano A, D'Ursi R, Scarcia R, Martino R, Miccoli A, Trabacca A (1992) Stress, depression and anxiety in primary headache sufferers: evalutaion by means of the SCL-90R. Headache Q 3(2):187-192

4. Breslau N, Merikangas K, Bowden CL (1994) Comorbidity of migraine and major affective disorders. Neurology 44[Suppl 7]:S17-S22

5. Devlen J (1994) Anxiety and depression in migraine. J R Soc Med 87(6): 338-341

6. Breslau N, Davis GC, Schultz L, Peterson EL (1994) Migraine and major depression: a longitudinal study. Headache 34:387-393
7. Breslau N, Davis GC, Andresik P (1992) Migraine, psychiatric disorders and suicide attempt: an epidemiologic study of young adults. Psychol Res 37(1):11-23

8. Guidetti V, Galli F, Fabrizi P, Giannantoni AS, Napoli L, Bruni O, Trillo S (1998) Headache and psychiatric comorbidity: clinical aspects and outcome in an 8-year follow-up study. Cephalalgia 18(7):453-462

9. Passchier J (1994) A critical note on psychophysiological stress research into migraine patients. Cephalalgia 14:194-198

10. Pietrini P, Guazzelli M (1997) Life events in the course of chronic diseases: A psychological myth or a psycho-neuro-biochemical loop? Clin Exp Rheumatol 15:125-128

11. De Benedittis G, Lorenzetti A (1992) The role of stressful life events in the persistence of primary headache: major events vs daily hassles. Pain 51:35-42

12. De Benedittis G, Lorenzetti A (1992) Minor stressful life events (daily hassles) in chronic primary headache: relationship with MMPI patterns. Headache 32:330-334
13. De Benedittis G, Lorenzetti A, Pieri A (1990) The role of stressful life events in the onset of chronic primary headache. Pain 40:65-75

14. Fernandez E, Sheffield J (1996) Relative contributions of life events versus daily hassles to the frequeney and intensity of headache. Headache 36(10):395-602

15. Gamsa A, Vikis-Freibergs V (1991) Psychological events are both risk factors in, and consequences of, chronic pain. Pain 44:271-277

16. Gruen RG, Folkman S, Lazarus RS (1988) Centrality and individual differences in the meaning of daily hassles. J Pers 56:743-762

17. Holmes TH, Rahe RH (1967) The social readjustment rating scale. J Psychosom Res 11:213-218

18. Kanner A, Coyne IC, Schaefer C, Lazarus RS (1981) Comparison of two modes of stress measurement: daily hassles and uplifts versus major life events. J Behav Med 4:1-39

19. Martin PR, Theunissen C (1993) The role of life event stress, coping and social support in chronic headaches. Headache 33(6):301-306 
20. Sarason IG, Johnson, JH, Siegel JM (1978) Assessing the impact of life changes: development of the life experiences survey. J Consult Clin Psychol 46:932-946

21. Sorbi MJ, Maassen GH, Spierings EL (1996) A time series analysis of daily hassles and mood changes in the 3 days before the migraine attack. Behav Med 22(3):103-113

22. Spierings EL, Sorbi M, Haimowitz, BR, Tellegen B (1996) Changes in daily hassles, mood, and sleep in the 2 days before a migraine headache. Clin J Pain 12(1):38-42

23. The Italian Collaborative Group for the Study of Psychopathological Factors in Primary Headaches (1999) Psychiatric comorbidity and psychosocial stress in patients with tension-type headache from headache centers in Italy. Cephalalgia 19:1-6
24. Headache Classification Committee of the International Headache Society (1988) Classification and diagnostic criteria for headache disorders, cranial neuralgias and facial pain. Cephalalgia 8[Suppl 7]:1-96

25. Robins LN, Wing J, Wittchen HV et al (1988) The composite international diagnostic interview. An epidemiologic instrument suitable for use in conjunction with different diagnostic systems in different cultures. Arch Gen Psychiatry 45(12):1069-1077

26. Tacchini G, Sironi J (1997) CIDI-c. Versione 1.1. Masson, Milano

27. - (1987) DSM-III-R: Diagnostic and statistical manual of mental disorders, 3rd edn. American Psychiatric Association, Washington DC

28. Myers JK, Weissman MM, Tischler GL et al (1984) Six-month prevalence of psychiatric disorders in three communities. Arch Gen Psychiatry 41:959-967
29. Marino S, Bellantuono C, Tansella M (1990) Psychiatric morbidity in general practice in Italy. A point-prevalence survey in a defined geographical area. Soc Psychiatry Psychiatr Epidemiology 22(2):67-72

30. Zelena D, Haller J, Halasz J, Makara GB (1999) Social stress of variable intensity: physiological and behavioural consequences. Brain Res Bull 48(3):297-302

31. Wright J, Deary IJ, Geissler PR (1991) Depression, hassles and somatic symptoms in mandibular dysfunction syndrome patients. J Dent 19(6):352-356

32. Johnson JG (1992) Life event categories differentially predict psychopathology symptom levels. J Psychol 126(3):301-307 